\title{
EFFECT OF IMAGINATION ON SPORT ACHIEVEMENTS OF NOVICE SOCCER PLAYERS
}

\author{
Aleksander N. Veraksa, \\ Aleksandra E. Gorovaya \\ Lomonosov Moscow State University \\ Moscow
}

\begin{abstract}
This article describes the connection between the use of types of mental imagery by athletes and the level of their imagination. Taking the model of imagery use suggested by K. Martin, S. Moritz and C. Hall, the authors used a Russian version of "The Sport Imagery Questionnaire" (SIQ) with soccer players 8, 10 and 14 years old. The data shows that subjects with a higher level of imagination are more inclined to use mental imagery in their practice. Age differences in types of imagery usage are shown. The results indicated that mental-imagery training can result in enhanced performance among junior athletes.
\end{abstract}

Keywords: mental imagery, level of athlete's imagination, SIQ, tests of movement skill.

Numerous sport performers intentionally employ imagery in their daily practice. Researchers in sport psychology indicate that elite athletes and their coaches employ imagery more than any other performanceenhancement technique. However, defining mental imagery is a difficult task. Currently, only limited consensus as to which conceptualizations represent accurate descriptions of the imagery experience exists (Morris et al., 2005). According to L. McAvinue within the field of sport psychology, mental imagery has been discussed under many headings, including motor imagery, mental imagery, movement imagery, mental training, imagery rehearsal, visualisation, kinaesthetic imagery, and visuomotor behavioural rehearsal (McAvinue \& Robertson, 2008). Overall imagery, visualization, mental rehearsal, etc. refer to "creating or recreating an experience in the mind" (Weinberg \& Gould, 2007, p. 296). Additionally,

The research was supported by the federal program "Scientific and scientific-pedagogical personnel of innovative Russia” for 2009-2013. 
R. Nideffer (Nideffer, 1979) argued that it is important to distinguish mental practice of athletes from general process of person's imagination. He stated that the process of mental training involves a detailed and intentional rehearsal and learning of a certain motor image throughout series of representations. General process of person's imagination differs from this process by spontaneity of the course and absence of the analysis of quintessential details.

Among the existing definitions, the classic description of mental imagery formulated by A. Richardson, is commonly used. Following his point of view we suggest that mental imagery refers to "all those quasi-sensory and quasi-perceptual experiences of which we are self-consciously aware and which exist for us in the absence of those stimulus conditions that are known to produce their genuine sensory or perceptual counterparts" (Richardson, 1969, pp. 2-3). According to J. Corbin mental training is the "repetition of a task, without observable movement, with the specific intent of learning" (Corbin 1972, p. 94). It is necessary to point out that mental training may not use imagery at all (it can include nonimage-based strategies, such as verbal rehearsal or self-talk). In general, these terms are regularly used with the least discrimination.

Athletes use imagery for many different purposes. K. Martin, S. Moritz and C. Hall (1999) developed an applied model of imagery use in sport that focuses on the various functions that imagery can serve in sport. Authors used A. Paivio's analytical framework as the basis for this model. Paivio (Paivio, 1985) argued that sport imagery plays both a cognitive and a motivational role in influencing behavior. Each role operates on a general or specific level. Martin et al. (1999) summarized and extended the original four Paivio categories into five classes of imagery use (see Table 1):

- cognitive general (CG)

- cognitive specific (CS)

- motivational general arousal (MG-A)

- motivational general mastery (MG-M)

- motivational specific (MS).

The model indicates that in various sport situations the function of imagery to be used should match the desired outcome. For example, if athletes wish to increase their self-confidence, they should employ MG-M imagery. 
Different types of mental imagery

Table 1

\begin{tabular}{|c|c|c|c|c|}
\hline & Motivation & & Cognitive & \\
\hline \multirow[t]{2}{*}{ Overview } & $\begin{array}{l}\text { Imagery use } \\
\text { for the purpose } \\
\text { of enhancing } \\
\text { performance }\end{array}$ & & \begin{tabular}{|l} 
Imagery used \\
as a learning \\
tool to improve \\
particular skills
\end{tabular} & \\
\hline & & Example & & Example \\
\hline Specific & $\begin{array}{l}\text { Imagery entails } \\
\text { imaging goal } \\
\text { achievement } \\
\text { and accomplish- } \\
\text { ment }\end{array}$ & $\begin{array}{l}\text { I imagine } \\
\text { other athletes } \\
\text { congratulating } \\
\text { me on a good } \\
\text { performance }\end{array}$ & $\begin{array}{l}\text { Mental rehears- } \\
\text { al of skills }\end{array}$ & $\begin{array}{l}\text { When learning } \\
\text { a new skill, I } \\
\text { imagine myself } \\
\text { performing it } \\
\text { perfectly }\end{array}$ \\
\hline General & $\begin{array}{l}\text { Refers to physi- } \\
\text { ological arousal } \\
\text { and affect }\end{array}$ & & \multirow[t]{3}{*}{$\begin{array}{l}\text { Mentally } \\
\text { rehearsing race } \\
\text { plans and strate- } \\
\text { gies of play }\end{array}$} & \multirow[t]{3}{*}{$\begin{array}{l}\text { I image each } \\
\text { section of an } \\
\text { event/game }\end{array}$} \\
\hline Arousal & $\begin{array}{l}\text { Imagery related } \\
\text { to arousal, re- } \\
\text { laxation, and } \\
\text { competitive } \\
\text { anxiety }\end{array}$ & $\begin{array}{l}\text { I image how } \\
\text { i pull myself } \\
\text { together in a } \\
\text { challenging } \\
\text { situation }\end{array}$ & & \\
\hline Mastery & $\begin{array}{l}\text { Used to imagine } \\
\text { being in control } \\
\text { and feeling } \\
\text { confident (i.e. } \\
\text { representative of } \\
\text { effective coping } \\
\text { and confidence } \\
\text { in challenging } \\
\text { situations) }\end{array}$ & $\begin{array}{l}\text { I imagine my- } \\
\text { self appearing } \\
\text { self-confident } \\
\text { in front of my } \\
\text { opponents }\end{array}$ & & \\
\hline
\end{tabular}

Hall et al. (Hall et al., 2005) compiled the Sport Imagery Questionnaire (SIQ) as a general instrument to assess athletes' use of the five cognitive and motivational functions of imagery. SIQ can be administered to athletes at any competitive level and in any sport. The SIQ comprises 30 questions with seven items corresponding to the CS subscale, six items representing the CG subscale, five items correlating with the MS subscale, six items representing the MG-A subscale, and six items 
comprising the MG- M. Each item is rated against a 7-point Likert-type scale with anchors of $1=$ rarely use that function of imagery and $7=$ often use that function of imagery. An average frequency score for the athletes' use of each of the five functions is then calculated. Thus, in the original version of the questionnaire, after the acquaintance with the extensional instruction, which defined some special terms used in the statements' text, athletes were asked to indicate (write in the blank appropriate number from the scale) "the degree to which the statement applies to you when you are practicing or competing in your sport" (Hall et al., 2005). Authors argued that SIQ is suitable for athletes 14 years of age and older.

Following the original version of the SIQ we developed a Russian version of this instrument. We made necessary modifications to the text of original version of questionnaire and the form of its presentation according to responses obtained from athletes $(\mathrm{N}=27$, age from 10 to 25 years).

Thus, our first goal in the study was to test hypotheses regarding the nature of the connections between the use of types of mental imagery by athletes (by administering Russian version of the SIQ) and the level of their imagination. In addition, our study was designed to investigate the age differences in types of imagery usage as well as specificity of the relationship between using imagery and performance.

Research (e.g., Barr \& Hall, 1992; Martin et al., 1999; White \& Hardy, 1995 etc.) and reviews of imagery literature (e.g., Driskell et al., 1994), suggest that imagery of a particular sport skill can improve physical performance of that skill. Moreover, taking the previous research in this field as a basis, Zhang Li-Wei et al. (Li-Wei, Qi-Wei, Orlick, \& Zitzelsberge, 1992) suggested that mental imagery may be useful for children as well as for grown up athletes. Therefore, our second goal in this study was to establish efficacy of the use of mental imagery on children's performance.

\section{Experiment 1}

\section{Participants}

Participants were represented by thirty one male soccer players, attending a sport school in Moscow, Russia: 13 players 8 years old; 11 players 10 years old and 7 players 14 years old. 


\section{Measures}

Torrance Tests of Creative Thinking (TTCT). Level of athlete's imagination was assessed with Torrance tests of creative thinking (verbal and figural forms), adapted in Russia (Shcheblanova, 1995). Verbal and figural forms of TTCT are used for studying different kinds of cognitive activity (visual and verbal respectively); however, following recommendations of the authors, we used both of them.

Sport Imagery Questionnaire (SIQ). To assess the use of imagery the Russian version of "The Sport Imagery Questionnaire" was administered. Completing of questionnaire was accompanied by the individual interview directed on specification of received answers.

We used test of movement skill (TS) as a measure of athlete's performance ratings. Test of movement skill is a standard test that is used in the context of soccer.

\section{Procedure}

In the first stage of this study, all participants completed TTCT, SIQ and TS. To establish relationship between various rates of figural and verbal forms TTCT, SIQ and TS correlation analysis by Brave - Pearson method was carried out. Statistic work was carried out with the help of SPSS 17.0 applied programs.

\section{Results and discussion}

The data of correlation analysis indicated a significant positive correlation between rates of figural form of TTCT and SIQ. Correlation between parameters of functions of imagery (cognitive and motivational) and parameters of fluency and elaboration (specific to figural form of TTCT) of thinking as well as between parameters of functions of imagery and parameter of total score of TTCT are most illustrative in this regard. For example the following correlations are significant (at the level $p<0,05)$ : rate of total score of figural form of TTCT with total rate of cognitive imagery $(r=0,632)$, rate of parameter of fluency with rate of motivational specific imagery $(\mathrm{r}=0,751)$, rate of elaboration with rate of cognitive specific imagery $(r=0,667)$. Thus, the following trend is displayed: rates of frequency of imagery use enhances with the increase of value rates of nonverbal creative thinking. In other words, subjects with a higher level of imagination are more inclined to use mental imagery in 
their practice. This trend was made evident by the words of participants who showed higher scores (on average for the group) on the figural form of TTCT. For example, Vlad S. (8;4) said: "Every time I'm taking a car ride to a practice session, I getting prepared for it...or I imagine playing at home... first my dad taught me, then I started doing it myself". Sergey Z. $(10 ; 2)$ noted "I first imagine how I want to hit, and then I hit".

At the same time, we found age differences in types of imagery usage. The results for 8-10 year old subjects indicated a significant positive correlation between rates of figural form of TTCT and rates of the SIQ that represent motivational functions of imagery use by athletes. For older subjects correlation were revealed between rates of figural form of TTCT and rates of the SIQ that represent both cognitive and motivational functions of imagery use by athletes. The fact may admit the following explanation. For one thing, 8 year old athletes do not have well-developed movement skills, which causes difficulties when trying to work them out mentally (cognitive imagery). L. Pikkenhein (Pikkenhein, 1980), for instance, states that the mechanism of mental actions correction can be effectively employed only when skills of real motor programs have been acquired, while there are no such limits with regard to motivational imagery. Besides, it is widely believed that logical thinking of most children at the age of 8 only starts developing, in other words, the imagination level of athletes of this age prevails over development of thinking. Hence it is evident that junior athletes are able to use motivational imagery, characterized by greater emotionality, rather than cognitive one.

The same pattern of results was found for relationship between SIQ and TS. For junior subjects correlation was revealed between TS and rates of the SIQ that represent motivational functions of imagery use by athletes, whereas for older subjects correlation between TS and rates of the SIQ revealed the presence of both functions of imagery. In addition, the content analysis of correlations between results of TTCT, SIQ and TS suggests the following tendency: athletes with higher level of imagination and more frequent use of mental imagery in their practice had better performance in movement skill tests. Notably, it is important that analysis reveals a significant (at the level $\mathrm{p}<0,05)$ correlation between: results of TS and parameters of elaboration $(r=0,706)$ and flexibility of thinking $(r=0,816)$; between TS and total rate of motivational imagery $(\mathrm{r}=0,92)$, TS and rate of motivational specific imagery $(\mathrm{r}=0,88)$ and TS and rate of motivational general mastery imagery $(r=0,574)$; between TS 
and total rate of cognitive imagery $(\mathrm{r}=0,916)$ : between TS and rate of cognitive specific imagery $(\mathrm{r}=0,88)$; as well as a significant correlation between results of TS and rate of motivational general arousal imagery $(\mathrm{r}=0,79)$ was found at the level of significance of 0,01 .

It should be marked that those of junior athletes who reported in interviews about intentional usage of mental imagery in their sports activity, would use specifically motivational imagery. More often junior athletes said that their imagery use was like "narrative picture" (e.g. they "hit" or "score" during the play situations that were made up by them). The main emphasis of these pictures is put on the outcome ("to score a goal"), rather than on a strategy or a technical aspect of goal achievement. Therefore it might be claimed that motivational (specific) imagery is used by junior athletes. Older athletes in their interview would report of the necessity for both, cognitive and motivational imagery use. Ivan K. (10;7) noticed before a practice session that making fuss was the main obstacle in his game: "I have to become more considering... attention to technique means we score". The importance of concentration was noted by Rashid R. (10;9): "If you want to hit well - you have to concentrate".

\section{Experiment 2}

\section{Procedure}

In the second stage of this study we tested the hypotheses regarding the efficacy of mental imagery use. Many studies had typically shown the positive effects of imagery use by showing an increase in performance for imagery groups as compared to control groups. Following this design the participants were randomly placed in two groups by the results of the Torrance Tests of Creative Thinking (TTCT). For the purpose of this study, however, groups were equalized by the level of athlete's imagination. One of them consisted of 8 and 10 years old soccer players who were assigned to the imagery-based intervention program (experimental group). A second group consisted of 8 and 10 year old soccer players who did not take part in imagery program (control group). Soccer players 14 years old did not participate in the experimental part of this study.

During the experimental part of the study, all subjects continued to participate in the same physical training as they had before the experiment. Prior to the administration of the intervention, a pre-test of move- 
ment skill was carried out. We used the test of movement skill (TS) as well as a measure of effectiveness of imagery-based intervention program. TS were conducted at the end of physical trainings that were accompanied by the imagery session.

Experimental group participants during 5 sessions were learning framework of mental-imagery training. First of all introduction session was carried out. It was done in a simple manner (adopted for children) and directed on explaining potential benefit of mental-imagery training and getting information from each participant about what part of TS was the most trying for him. Imagery sessions were conducted as a part of physical trainings. Participants were instructed to recreate a TS performance in their mind. They were asked to generate "lifelikeness" images, using both the internal and external perspectives and involve kinesthetic sensations of the skill. Each imagery session lasted for approximately 15 minutes and included about 4 trials of TS' mental rehearsal. We also encouraged players to practice imagery just before a real TS performance.

\section{Results and discussion}

Performance ratings were calculated as average results of TS performance by each participants group.

Results for 8 year old athletes. The control group results showed only an $8 \%$ improvement in TS. The imagery group experienced a $31 \%$ improvement.

Results for 10 year old athletes. The control group results showed a 18, $7 \%$ improvement in TS. The imagery group experienced a 35\% improvement.

As we see, 8 year old athletes gain more profit through imagery training. This can be explained in the following manner: the movement skills of 10 year old athletes (which are necessary for performing TS) are more automatic than those of 8 year old athletes. Probably, additional techniques of movement-learning are much more useful to junior athletes in connection with this. In addition, as we have mentioned before, visual forms of thinking of athletes of this age prevails over logical forms of thinking, which probably facilitates mastering of mental-imagery training for them. 


\section{General conclusions}

Although Nideffer believed that mental practice of athletes differs from general process of person's imagination, this study employing a Russian version of the SIQ has revealed a significant connection between the use of types of mental imagery by athletes and the level of their imagination. Therefore it might be claimed that higher level of imagination provides framework for imagery use in junior athletes' performance enhancement.

The study also showed age differences in types of imagery usage. The results indicated that 8-10 year old athletes use more often motivational functions of imagery as compared with older children using both cognitive and motivational functions.

The study indicated that age-appropriate use of types of mental imagery significantly related to efficiency of sport performance. This finding means that mental-imagery training should match athletes' age and individual characteristics.

The results indicated that mental-imagery training can result in enhanced performance among junior athletes. Also, the age differences in effectiveness of imagery are shown.

\section{References}

Barr, K., \& Hall, C. (1992). The use of imagery by rowers. International Journal of Sport Psychology, 23.

Corbin, C. (1972). Mental practice. In W.P. Morgan (Ed.), Ergogenic aids and muscular performance. N.Y.: Academic Press, pp. 94-118.

Driskell, J.E. et al. (1994). Does Mental Practice Enhance Performance? Journal of Applied Psychology, 4.

Hall, C. et al. (2005). Sport Imagery Questionnaire: Test Manual. West Virginia: Fitness Information Technology.

Li-Wei Z., Qi-Wei M., Orlick, T., \& Zitzelsberger, L. (1992). Mental Training for Children. The Sport Psychologist, 6(3), 230-241.

Martin, K., Moritz, S., \& Hall, C. (1999). Imagery use in sport: A literature review and applied model. The Sport Psychologist, 13, 245-268.

McAvinue, L., \& Robertson, I. (2008). Measuring motor imagery ability: A review. European journal of cognitive psychology, 20, 232-251.

Morris, T., Spittle, M., \& Watt, A. (2005). Imagery in sport. Champaign, IL: Human Kinetics. 
Nideffer, R. (1979). Psihologija sorevnujuschegosja sportsmena [Psychology of competitive athletes] (pp. 160-185). Moscow: Fizkultura i Sport.

Paivio, A. (1985). Cognitive and motivational functions of imagery in human performance. Canadian Journal of Applied Sport Sciences, 10, 22-28.

Pikkenhein, L. (1980). Neurophysiological mechanisms of ideomotor training. Voprosy Psykhologii, 3, 116-121.

Richardson, A. (1969). Mental imagery. London: Routledge \& Kegan.

Shcheblanova, E., \& Averina, I. (1995). Express-test of creative thinking. Moscow: Intor.

Weinberg, R., \& Gould, D. (2007). Foundations of sport and exercise psychology. 4th ed. Champaign, IL: Human Kinetics.

White, A., \& Hardy, L. (1995). Use of different imagery perspectives on the learning and performance of different motor skills. British Journal of Psychology, 86. 